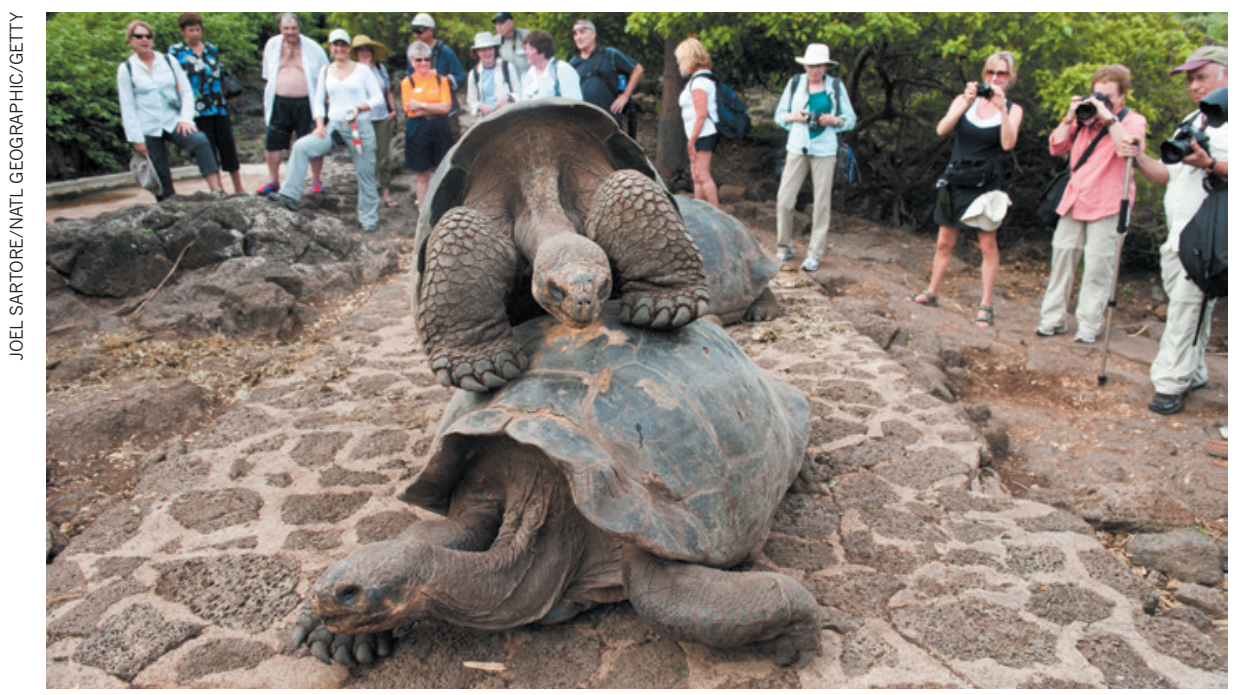

Tortoises at the Charles Darwin Research Station on Santa Cruz in the Galapagos Islands.

\title{
Key Galapagos research station in trouble
}

\section{Local government's closure of gift shop could doom Charles Darwin Foundation.}

\section{BY ALESZU BAJAK}

$\mathrm{F}$ or more than half a century, the Charles Darwin Foundation (CDF) has supported a thriving research station in Ecuador's Galapagos Islands. Scientists at the station have helped to bring the iconic Galapagos tortoise back from the brink of extinction and to eradicate invasive goats from Isabela, the largest island in the Galapagos archipelago.

But that long legacy is being threatened by a spat with the local government, which could force the Charles Darwin Research Station to close. In July, officials on Santa Cruz island ordered the CDF to shut its lucrative gift shop in the town of Puerto Ayora, citing complaints from restaurateurs and shop owners who said that the store was siphoning away their business. That has deprived the foundation of at least US $\$ 8,000$ per week in income; total losses could reach $\$ 200,000$ if the shop remains closed for the rest of the year, the foundation says.

"The closure of the store basically ruined our 2014 budget," says CDF president Dennis Geist, a volcanologist who has studied Galapagos sites for 30 years. "We have no endowment. We don't even have any reserve funds. The closing of the Darwin station is a very realistic possibility right now."

On 24 November, the CDF's governing body met in Quito, Ecuador. Its voting members, who include employees of the Ecuadorian federal government, agreed to form a working group "to strategically secure the operation of the research station".

But the financial troubles are already affecting operations at the station, which employs around 65 people and works with more than 100 international scientific collaborators. Although the gift shop provides just $10 \%$ of the foundation's revenue, its closure has had cascading effects, says CDF executive director Swen Lorenz. "We have already lost a significant donation from someone who said that if the government of Ecuador doesn't support us having a souvenir shop, then he won't support us with a donation," he says. "We're two and a half months late with salary, projects haven't been running, and we've had one staff member leave."

Alex Hearn, director of conservation science at the Turtle Island Restoration Network, an environmental advocacy group based in Olema, California, says that the closure of Darwin station would be a major blow. Nearly every scientist who has worked in the Galapagos has dealt either directly or indirectly with the CDF, says Hearn, who coordinated fisheries research at the station from 2002 to 2008.

He still works closely with scientists there on fisheries and shark research. "I don't have to jump on a plane every time I need some data," he says. "I know the research can be done, and done well." - 